\title{
BMJ Open Socioeconomic position, symptoms of depression and subsequent mental healthcare treatment: a Danish register- based 6-month follow-up study on a population survey
}

\author{
Aake Packness, ${ }^{1,2}$ Anders Halling, ${ }^{3}$ Lene Halling Hastrup, ${ }^{2}$ Erik Simonsen, ${ }^{2,4}$ \\ Sonja Wehberg, ${ }^{5}$ Frans Boch Waldorff ${ }^{1}$
}

To cite: Packness A, Halling A, Hastrup LH, et al. Socioeconomic position, symptoms of depression and subsequent mental healthcare treatment: a Danish register-based 6-month follow-up study on a population survey. BMJ Open 2018;8:e020945. doi:10.1136/ bmjopen-2017-020945

- Prepublication history and additional material for this paper are available online. To view these files, please visit the journal online (http://dx. doi org/10.1136/bmjopen-2017020945).

Received 2 December 2017 Revised 13 June 2018 Accepted 17 July 2018
D) Check for updates

(c) Author(s) (or their employer(s)) 2018. Re-use permitted under CC BY-NC. No commercial re-use. See rights and permissions. Published by BMJ.

For numbered affiliations see end of article.

\section{Correspondence to} Mr Aake Packness; apackness@health.sdu.dk, aake.packness@gmail.com

\section{ABSTRACT}

Objective Examine whether the severity of symptoms of depression was associated with the type of mental healthcare treatment (MHCT) received, independent of socioeconomic position (SEP).

Design Register-based 6-month follow-up study on participants from the Danish General Suburban Population Study (GESUS) 2010-2013, who scored the Major Depression Inventory (MDI).

Participants Nineteen thousand and eleven respondents from GESUS.

Interventions The MHCT of the participants was tracked in national registers 4 months prior and 6 months after their MDI scores. MHCT was graduated in levels. SEP was defined by years of formal postsecondary education and income categorised into three levels. Data were analysed using logistic and Poisson regression analyses.

Outcomes MHCT included number of contacts with: general practitioner (GP), GP mental health counselling, psychologist, psychiatrist, emergency contacts, admissions to psychiatric hospitals and prescriptions of antidepressants.

Results For 547 respondents with moderate to severe symptoms of depression there was no difference across SEP in use of services, contact $(\mathrm{y} / \mathrm{n})$, frequency of contact or level of treatment, except respondents with low SEP had more frequent contact with their GP. However, of the 547 respondents, $10 \%$ had no treatment contacts at all, and $47 \%$ had no treatment beyond GP consultation. Among respondents with no/few symptoms of depression, postsecondary education $\geq 3$ years was associated with more contact with specialised services (adjusted OR (aOR) 1.92; $95 \% \mathrm{Cl} 1.18$ to 3.13); however, this difference did not apply for income; additionally, high SEP was associated with fewer prescriptions of antidepressants (education aOR 0.69; $\mathrm{Cl} 0.50$ to 0.95 ; income aOR 0.56, $\mathrm{Cl} 0.39$ to 0.80 ) compared with low SEP.

Conclusion Participants with symptoms of depression were treated according to the severity of their symptoms, independent of SEP; however, more than half with moderate to severe symptoms received no treatment beyond GP consultation. People in low SEP and no/few symptoms of depression were more often treated with antidepressants. The study was approved by The Danish
Strengths and limitations of this study

- The design of this study, combining data from a population survey on depression symptom scores with prospective register data on healthcare use and medication, is unique in health service research on treatment of people with symptoms of depression.

- The study design made it possible to reduce the inherent problem of recall bias in these types of studies.

- The actual reasons for treatment contacts or for prescription of antidepressants were not known; they could have been caused by disorders other than depression.

- The study sample was generally better educated than the population they were sampled from.

Data Protection Agency Journal number 2015-41-3984. Accessible at: https://www.datatilsynet.dk/fortegnelsen/ soeg-i-fortegnelsen/

\section{INTRODUCTION}

Equal access to healthcare based on need and the reduction of health inequalities are major policy objectives in most countries in the Organisation for Economic Co-operation and Development (OECD). ${ }^{1}$ Similarly, the WHO states that addressing social inequalities contributes significantly to the health and well-being of individuals and countries. ${ }^{2}$

Sustained economic hardship can lead to poorer physical, psychological and cognitive functioning, ${ }^{3}$ and is furthermore associated with a higher prevalence of mental health problems. ${ }^{4}$ Specifically, depressive disorders are more prevalent among people in a low socioeconomic position $(\mathrm{SEP})^{5}$ and are enhanced by worsening socioeconomic circumstances. ${ }^{6}$ Whereas low SEP is an outcome of schizophrenia, it is a determinant 
for depression. ${ }^{78}$ Additionally, depression is a major health problem, globally ranked as the single largest contributor to non-fatal health loss, accounting for $7.5 \%$ overall in years lived with disability. ${ }^{9}$ It is estimated that life expectancy is reduced by 14 years for men and 10 years for women treated for severe depression. ${ }^{10}$

Equity in access to healthcare is commonly defined as equal access for equal need. However, both access and need are ambiguous concepts. ${ }^{11}$ It has been documented that patients in high SEP use more specialised healthcare services, ${ }^{12} 13$ also within mental healthcare; ${ }^{14}$ yet there remains a gap between those in need of mental healthcare and those who receive it. ${ }^{15-17}$ Additionally, not all users of mental healthcare are in clinical need. ${ }^{18}$ As for depression and anxiety disorders, some studies have found access to specialist care to be reflective of clinical need, with little inequality in SEP, ${ }^{19}{ }^{20}$ whereas others report specialised mental health services are not provided to persons in low SEP according to need, ${ }^{21}{ }^{22}$ or that higher SEP is associated with more use of specialised mental health services. ${ }^{23} 24$ This uncertainty and the fact that depressive disorders are widespread and more common among persons in lower SEP makes these disorders both relevant and well suited to evaluate the capability of healthcare systems to address the needs of economically deprived citizens. Depression is a serious disorder with extensive personal, social and economic consequences, which makes its treatment an important issue and health equality an urgent cause.

\section{OBJECTIVES}

We aimed to evaluate whether the Danish healthcare system delivers equal treatment to patients with symptoms of depression. We defined mental healthcare treatment (MHCT) as the use of specific healthcare services related to the treatment of depressive disorders, as well as treatment with antidepressants.

The objective was to examine if the severity of symptoms of depression (need) was associated with the MHCT received, independent of SEP in both type and frequency of treatments, and highest gained treatment level within 6 months following a symptom score in a survey study.

\section{METHOD \\ Design}

A 6-month follow-up study on respondents with symptoms of depression, combining survey data with register data on MHCT.

\section{Setting: the Danish healthcare system}

Healthcare is tax-funded in Denmark and free at delivery, except for dental care and visits to psychologists for adults, which are both partly subsidised. ${ }^{25}$ The general practitioner (GP) acts as a gatekeeper to more specialised care. Treatment by a psychologist is subsidised for patients with specific conditions, such as reaction to specific traumatic events, moderate depression and, specifically for citizens between 18 years and 38 years, also moderate anxiety disorders. In 2014, the co-payment for a psychologist appointment was equivalent to $€ 44$ per session. ${ }^{26}$ Each psychologist is obliged to obtain a special authorisation from the Danish Supervisory Board of Psychological Practice in order to be subsidised.

\section{Study population and data sources}

The study was conducted as a follow-up study on mental healthcare utilisation and use of antidepressants, examining participants who scored high on symptoms of depression in the Danish General Suburban Population Study

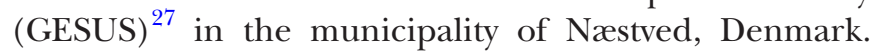
The municipality of Næstved is located $90 \mathrm{~km}$ south of the capital Copenhagen. It has a total population of 81000 and a socioeconomic index score 4\% lower than the 2013 national average. ${ }^{28}$ The GESUS data were collected from January 2010 through October 2013. The aim of GESUS was to facilitate epidemiological and genetic research by using information from questionnaires, health examinations, biochemical measurements, genetic variants and public registers to analyse the occurrence of comorbidities (eg, diabetes, cardiovascular disease, pulmonary disease and cancer) and mortality. All citizens over the age of 30 years were invited, as were a random selection of a quarter of citizens between 20 years and 30 years of age. The study included 21253 participants, equivalent to $43 \%$ of the invited citizens; the median age of participants was 56 years and that of non-participants 52 years. Data from the self-administered GESUS questionnaire were used in the present study.

Persons with permanent residence in Denmark are registered in the Danish Civil Registration System (CRS) ${ }^{29}$ and are assigned a unique 10-digit identification number, the Central Personal Register (CPR) number. The CPR number was registered in the survey data and thus provided a way to match respondents with information on their age and gender, and also made it is possible to identify the individuals in all public data registers in Denmark. In addition to the data sources already mentioned, data concerning vital status and dates of migration were gathered from the CRS as well.

Using the CPRs from GESUS, we linked to the national registers and tracked the use of healthcare services and antidepressants for 4 months (120 days) prior and 6 months (180 days) after the respondents entered the GESUS study, or until their death or migration, if that occurred before. Data from national registers covered the years 2010-2014; however, in order to fit a time frame of 4 months prior to index date, the sample was reduced to include only respondents entering the GESUS study from May 2010, due to lack of data availability from 2009. The period of 4 months prior to the study was chosen assuming active treatment would include a treatment appointment or renewed prescription at least every $3-4$ months.

\section{Independent variables}

Data on independent variables came from GESUS. 


\section{Measure of need}

Depression was chosen as an expression of need, with the Major Depression Inventory (MDI) as a measurement tool, extracted from the GESUS questionnaire. The MDI is based on the 12-item Likert Scale and has been found to have adequate internal and external validity for defining different stages of depression. ${ }^{30}$ The MDI is based on the International Classification of Deseases version 10 (ICD-10) diagnostic criteria for depressive disorder, ${ }^{31}$ with scores ranging from 0 to 50 : scores $\leq 20$ do not indicate depression; mild depression is defined as a score from 21 to 25 ; moderate depression from 26 to 30; and severe depression from 31 to $50 .{ }^{32}$ In the study, we collapsed moderate and severe depression into the same category, reducing the categories to three in order to gain statistical power: no/few symptoms (summed MDI 0-20), mild symptoms (summed MDI 21-25), and moderate/severe symptoms (summed MDI 26+). This splitting of symptomatic individuals into only two groups (mild or moderate/ severe) was supported by the recommended therapeutic approach at the time: patients with mild symptoms were recommended 'watchful waiting' and perhaps supportive consultations, whereas patients with moderate to severe depression were recommended antidepressants and therapy by a psychologist or a psychiatrist. ${ }^{33}$ If more than two items were missing in the MDI, the score was categorised as missing. ${ }^{34}$

\section{Socioeconomic position}

SEP is commonly measured by income, occupation, housing tenure, or education; higher education in particular is known to predict higher response rates in questionnaires. ${ }^{35}$ Education and income were chosen as measures of SEP in this study due to the respondents' age distribution skewing older than the general population; older age groups tend to have lower education, and they also have lower incomes, but occupation is not a useful SEP measurement for retired individuals. Education was classified as, no postsecondary education: if the respondent did not complete any postsecondary education; 1-3 years postsecondary education: for vocational education of 1-3 years; or for academy/ professional graduates of 1-3 years; $3+$ postsecondary education: for baccalaureate who completed 3-4 years and academic for those who completed graduate study of $\geq 5$ years. Students were categorised at the level that their studies would end in, for example, students in doctoral programs would be categorised as academics even though they had not yet completed 5 years of graduate study.

Information on income was also extracted from the GESUS questionnaire, where it was reported in Danish Kroner (Kr). Kr100 equals $€ 13.42$, a fixed exchange rate for many years. Income was grouped into three equal groups: Less than Kr300 000; Kr300000-599999; and $\mathrm{Kr} 600$ 000+and reported as: $<€ 40250$; $\geq € 40250<$ $€ 80499$; or $\geq € 80500$.
When both income and education show the same association to an outcome, it will be addressed as an association to SEP; otherwise the association will be addressed to the variable in question (income/education).

\section{Extrinsic variables}

Sociodemographic data included age, gender, marital status and cohabitation status.

Information on somatic comorbidity included: previous acute myocardial infarction, arteriosclerosis, angina pectoris, stroke, cancer, diabetes mellitus, hyperthyroidism or hypothyroidism. The somatic disorders were all grouped into one variable. Previous depressive episodes were registered separately.

Present medication covered self-reported use of antidepressants. Respondents defined as being in present treatment included both participants who reported use of antidepressants and participants identified in registers, as described below, who had redeemed a prescription for antidepressants and/or had contact with a psychiatrist and/or a psychologist within 4 months prior to the date of returning the questionnaire (in the following termed the index date) with the depression score.

\section{Dependent variables}

Data on dependable variables were drawn from national registers.

The outcome variables were graded according to the stepwise treatment of increasing intensity for depression as it was recommended in the Danish national guidelines at the time. ${ }^{25}$ The guidelines start with (\#1) Counselling and (\#2) Therapy provided by the GP, followed by (\#3) Prescription of antidepressants, followed by (\#4) Referral to therapy with a psychologist, then (\#5) Referral to treatment by a psychiatrist, and finally (\#6) Referral to outpatient public psychiatrist or eventually (\#7) Inpatient treatment at a psychiatric hospital (see code definitions in online supplementary table 1; an additional \#0 refers to No treatment contact). Emergency visits to a psychiatric hospital were included in the category of hospital contacts. The more severe or non-respondent the depression is to the prescribed treatment, the higher the patient is supposed to move in the recommended treatment hierarchy. Treatment by psychologists (step \#4) or psychiatrists (steps \#5 and \#6), whether private or public, were pooled into one group in some analyses due to low numbers of observations. Data on the utilisation of private psychiatrists, psychologists and GPs were drawn from the Danish National Health Service Register for Primary Care. ${ }^{36}$ For psychologists, only subsidised services are in the register. Respondents covered by private insurance and treated for depression or anxiety are included in the data, as insurance agencies require referral from GPs to compensate the patient.

Mental health counselling (MHC) provided by a GP consists of at least two talks within the first 6 months and up to seven talks within 1 year. This type of therapeutic 
counselling is registered and paid as additional reimbursement to the GP. In the study, this service was termed MHC by GP. Topics for ordinary consultations by GP are not registered in the national registers.

Data on prescriptions for antidepressants (Anatomical Therapeutic Chemical (ATC) Classification System N06A) were extracted from the Danish National Prescription Registry. ${ }^{37} 38$ However, bupropion (ATC $\mathrm{N} 06 \mathrm{~A} \times 12$ ), which is approved for the treatment of depression in some countries, was excluded from this study since it is only prescribed for smoking cessation in Denmark.

Information concerning public inpatient and outpatient psychiatric treatment was drawn from the Danish National Patient Register ${ }^{39}$ (ICD 10 coded F00 - F99).

\section{Statistical analyses}

First, we estimated the association between SEP and the different binary outcome variables (that is, the five different types of healthcare contacts: No healthcare contact, GP consultation, MHC by GP, Antidepressants and Specialised mental health services) in separate logistic regression models, both univariable and multivariable. Each model was stratified into three MDI categories: no/few symptoms $(\mathrm{MDI}<21)$, symptoms of mild depression (MDI 21-25), and symptoms of moderate to severe depression (MDI $\geq 26$ ). The SEP category 'No postsecondary education and income $<€ 40250$ ' was used as the reference category. To examine a possible interaction between SEP and the MDI category, we employed logistic regression models for each outcome, with patients having No postsecondary education/<€40250 and no/few depression symptoms as key reference.

Second, in order to evaluate differences in visits and prescription rates, we estimated incidence rate ratios (IRRs) by Poisson regression models for each type of contact (GP consultation, MHC by GP, Antidepressants and Specialised mental health services). For each type of contact, analyses were restricted to those patients who had at least one contact. For exposure, death and emigration within 180 days after index date were taken into consideration. As above, analyses were stratified into MDI category, and the SEP category 'No postsecondary education and $<€ 40250$ ' was used as a reference category.

Finally, we performed a linear regression analysis for the effect of combined SEP and MDI category on the highest reached treatment level (see treatment progression described above). The treatment levels were categorised as shown in online supplementary table 1 ( 0 : no treatment/contact; 1: GP consultation; 2: MHC by GP; 3 : antidepressants; 4: psychologist; 5 : private psychiatrist; 6: public psychiatrist; 7: psychiatric hospital). Patients having No postsecondary education/ $<€ 40250$ and no/few depression symptoms were the key reference groups.

All multivariable regression models included age (20-59 years versus $60+$ years), gender, present treatment with antidepressants, and psychologist or psychiatrist $(y e s / n o)$, in addition to the variable studied in the univariate (crude) analysis. In analyses including income, cohabitation was also included.

The significance level was 5\% throughout, and all reported CIs were 95\%. All statistical analyses were performed using Stata V.14. ${ }^{40}$

\section{PATIENT AND PUBLIC INVOLVEMENT}

The study did not involve patients or public in planning or execution.

\section{ETHICS}

Access to data from GESUS was approved by the GESUS board in December 2015. The data were stored in a server at Statistics Denmark. The collection and handling of the data have been approved by the Danish Data Protection Agency, journal number: 2015-41-3984. Approval by an ethics committee is not required for register studies in Denmark.

\section{RESULTS}

The study included 19011 respondents from the GESUS study; the original number of 21253 was reduced by 1627 respondents who entered before May 2010 due to data unavailability for 2009. The respondents were further reduced by an additional 615 who did not have a valid MDI score (see flow chart, supplementary figure $1)$. Twenty-nine deaths and four persons emigrating were included in the analysis only until death or migration. In all, 988 (5.2\%) had symptoms of depression. Of these, 441 had symptoms of mild depression and 547 had symptoms of moderate and severe depression, and of the latter group 271 were rated severe.

The baseline characteristics of the study sample are shown in table 1 , in total, and stratified by severity of symptoms of depression. Respondents with symptoms of mild to severe depression tended to be younger, included more singles, were living without a partner and were without formal education, compared with those with no/few symptoms.

In the study sample respondents with no education beyond the secondary level were under-represented and constituted half the proportion of the study population, according to Statistics Denmark; and the proportion with more than 3 years of postsecondary education was $32 \%$ in the sample compared with $19 \%$ in the population in Næstved. ${ }^{41}$

Table 2 shows ORs for MHCT contacts. Among respondents with no/few symptoms, the group with three or more years of postsecondary education was $30 \%$ more likely to have no healthcare contacts at all when compared with the group without postsecondary education (adjusted OR (aOR) 1.32 , CI 1.18 to 1.49 ). Similarly were respondents in the highest income group 66\% more likely to have no healthcare contacts at all when compared with the lowest income group (aOR 1.66, CI 1.46 to 1.89). 
Table 1 Baseline characteristics of the study sample by MDI grade

\begin{tabular}{|c|c|c|c|c|c|}
\hline MDI Score & All & MDI $<21$ & MDI 21-25 & MDI 26+ & MDI missing \\
\hline Symptoms of depression & n (\%) & None/few & Mild & Moderate./severe $§$ & NA \\
\hline All & $19626(100)$ & $18023(100)$ & $441(100)$ & $547(100)$ & $615(100)$ \\
\hline \multicolumn{6}{|l|}{ In treatment† } \\
\hline No & $18076(92.1)$ & $16860(93.5)$ & $334(75.7)$ & $335(61.2)$ & $547(88.9)$ \\
\hline Yes & $1550(7.9)$ & $1163(6.5)$ & $107(24.3)$ & $212(38.8)$ & $68(11.1)$ \\
\hline \multicolumn{6}{|l|}{ Gender } \\
\hline Male & $8927(45.5)$ & 8349 (46.3) & $162(36.7)$ & $168(30.7)$ & \\
\hline Female & $10699(54.5)$ & $9674(53.7)$ & $279(63.3)$ & $379(69.3)$ & \\
\hline \multicolumn{6}{|l|}{ Age group, years } \\
\hline $20-29$ & $294(1.5)$ & $266(1.5)$ & $10(2.3)$ & $17(3.1)$ & \\
\hline $30-39$ & $2382(12.1)$ & 2206 (12.2) & $79(17.9)$ & $86(15.7)$ & \\
\hline $40-49$ & $4186(21.3)$ & 3891 (21.6) & $106(24)$ & $146(26.7)$ & \\
\hline $50-59$ & $4417(22.5)$ & $4100(22.7)$ & $115(26.1)$ & $144(26.3)$ & \\
\hline $60-69$ & $5123(26.1)$ & 4771 (26.5) & $74(16.8)$ & $93(17)$ & \\
\hline $70+$ & $3224(16.4)$ & 2789 (15.5) & $57(12.9)$ & $61(11.2)$ & \\
\hline \multicolumn{6}{|l|}{ Marital status } \\
\hline Married & $13398(68.3)$ & $12519(69.5)$ & $234(53.1)$ & $259(47.3)$ & \\
\hline Separated/divorced & $2174(11.1)$ & $1936(10.7)$ & $71(16.1)$ & $117(21.4)$ & \\
\hline Widow/er & $1385(7.1)$ & $1172(6.5)$ & $37(8.4)$ & $45(8.2)$ & \\
\hline None of the above & 2669 (13.6) & $2396(13.3)$ & $99(22.4)$ & $126(23)$ & \\
\hline \multicolumn{6}{|l|}{ Cohabitating } \\
\hline No & $4342(22.1)$ & $3745(20.8)$ & $147(33.3)$ & $217(39.7)$ & \\
\hline Yes (including missing) & $15284(77.9)$ & $14278(79.2)$ & $294(66.7)$ & $330(60.3)$ & \\
\hline \multicolumn{6}{|l|}{ Education } \\
\hline None (No postsecondary) & $2988(15.2)$ & $2502(13.9)$ & $93(21.1)$ & $136(24.9)$ & \\
\hline Vocational/1-3years (1-3years postsecondary) & $8227(41.9)$ & 7645 (42.4) & $169(38.3)$ & $199(36.4)$ & \\
\hline Academy/professional <3years (1-3years postsecondary) & $2156(11)$ & $2005(11.1)$ & $56(12.7)$ & $58(10.6)$ & \\
\hline Baccalaureate/ $3-4$ years ( $3+$ years postsecondary) & $5024(25.6)$ & $4706(26.1)$ & $104(23.6)$ & $137(25)$ & \\
\hline Academic $/ 5+$ years $(3+$ years postsecondary) & $1231(6.3)$ & $1165(6.5)$ & $19(4.3)$ & $17(3.1)$ & \\
\hline \multicolumn{6}{|l|}{ Income } \\
\hline Less than $\mathrm{Kr} 150.000(<€ 40250)$ & $1063(5.4)$ & $847(4.7)$ & $38(8.6)$ & $69(12.6)$ & \\
\hline Kr150000-299999 (<€40250) & $3406(17,4)$ & $3003(16.7)$ & $100(22.7)$ & $139(25.4)$ & \\
\hline Kr300000-449999 $(\geq € 40250<€ 80500)$ & $3601(18.3)$ & $3344(18.6)$ & $73(16.6)$ & $98(17.9)$ & \\
\hline Kr450000-599000 ( $€ € 40250<€ 80500)$ & $3025(15.4)$ & $2863(15.9)$ & $64(14.5)$ & $66(12.1)$ & \\
\hline Kr600000-749999 ( $\geq € 80500)$ & $3245(16.5)$ & $3086(17.1)$ & $74(16.8)$ & $64(11.7)$ & \\
\hline Kr750000-899999 ( $\geq € 80500)$ & $1856(9.5)$ & $1794(10)$ & $22(5)$ & $29(5.3)$ & \\
\hline Kr900000-1049999 ( $\geq € 80500)$ & $693(3.5)$ & $667(3.7)$ & $12(2.7)$ & $9(1.6)$ & \\
\hline Kr1050000 + (z€80500) & $706(3.6)$ & $691(3.8)$ & $8(1.8)$ & $5(0.9)$ & \\
\hline Missing & $2031(10.3)$ & $1728(9.6)$ & $50(11.3)$ & $68(812.4)$ & \\
\hline \multicolumn{6}{|l|}{ Comorbidity former depression } \\
\hline No & $16755(85.4)$ & $15826(87.8)$ & $255(57.8)$ & $210(38.4)$ & \\
\hline Yes & $2484(12.7)$ & $1917(10.6)$ & $173(39.2)$ & $319(58.3)$ & \\
\hline Missing & $387(2)$ & $280(1.6)$ & $13(2.9)$ & $18(3.3)$ & \\
\hline \multicolumn{6}{|l|}{ Comorbidity somatic, allł } \\
\hline No & $13791(70.3)$ & $13109(72.7)$ & $195(44.2)$ & $168(30.7)$ & \\
\hline Yes & $5835(29.7)$ & $4914(27.3)$ & $246(55.8)$ & $379(69.3)$ & \\
\hline \multicolumn{6}{|l|}{ Medication antidepressants§ } \\
\hline No & $18537(94.5)$ & $17213(95.5)$ & $363(82.3)$ & $385(70.4)$ & $576(93.7)$ \\
\hline Yes & 1089 (5.5) & $810(4.5)$ & $78(17.7)$ & $162(29.6)$ & $39(6.3)$ \\
\hline
\end{tabular}

*Moderate or severe.

tIn treatment at index date or 120 days before by psychologist, psychiatrist or antidepressant prescription, according to GESUS or registers.

†Somatic comorbidities: ischaemic heart disease, diabetes, cancer, metabolic diseases.

$\S$ Replied in questionnaire.

GESUS, General Suburban Population Study; MDI, Major Depression Inventory. 
Table 2 ORs for type of mental healthcare treatment by education level and income level stratified by MDI grade

\begin{tabular}{|c|c|c|c|c|c|c|}
\hline \multirow{2}{*}{$\begin{array}{l}\text { Symptoms, depression } \\
\text { No contact at all }\end{array}$} & \multicolumn{2}{|l|}{ No/few (MDI<21) } & \multicolumn{2}{|l|}{ Mild (MDI 21 to 25) } & \multicolumn{2}{|c|}{ Moderate/severe (MDI>25) } \\
\hline & Crude OR & OR (adjusted)* & Crude OR & OR (adjusted)* & Crude OR & OR (adjusted)* \\
\hline Education & ( $\mathrm{n}=18023$ patients) & & ( $n=441$ patients) & & ( $\mathrm{n}=547$ patients) & \\
\hline No postsecondary education & Ref & Ref & Ref & Ref & Ref & Ref \\
\hline 1-3years postsecondary & $1.26(1.13$ to 1.40$)$ & 1.10 (0.98 to 1.23$)$ & 1.96 (0.91 to 4.22$)$ & 1.62 (0.71 to 3.67$)$ & 1.73 (0.79 to 3.77$)$ & $1.62(0.72$ to 3.65$)$ \\
\hline $3+$ years postsecondary & 1.54 (1.38 to 1.72$)$ & 1.32 (1.18 to 1.49$)$ & 2.38 (1.05 to 5.38$)$ & 2.01 (0.84 to 4.83$)$ & $1.99(0.87$ to 4.55$)$ & 1.79 (0.76 to 4.23$)$ \\
\hline Income & $(n=16295)$ & & $(n=391)$ & & $(n=479)$ & \\
\hline Income $<€ 40250$ & Ref & Ref† & Ref & Ref† & Ref & Ref† \\
\hline Income $\geq € 40250<€ 80500$ & 1.69 (1.53 to 1.87$)$ & 1.39 (1.24 to 1.56$)$ & 1.20 (0.62 to 2.33$)$ & 0.79 (0.36 to 1.76$)$ & $1.74(0.89$ to 3.40$)$ & 1.59 (0.72 to 3.52$)$ \\
\hline Income $\geq € 80500$ & 2.27 (2.06 to 2.51$)$ & 1.66 (1.46 to 1.89$)$ & 1.90 (0.99 to 3.63$)$ & 1.35 (0.55 to 3.33$)$ & $1.16(0.51$ to 2.63$)$ & 1.04 (0.38 to 2.82$)$ \\
\hline \multicolumn{7}{|l|}{ GP consultation } \\
\hline No postsecondary education & Ref & Ref & Ref & Ref & Ref & Ref \\
\hline $1-3$ years postsecondary & $0.80(0.72$ to 0.89$)$ & $0.92(0.82$ to 1.02$)$ & $0.52(0.26$ to 1.06$)$ & 0.64 (0.31 to 1.35$)$ & $0.68(0.35$ to 1.31$)$ & 0.70 (0.36 to 1.37$)$ \\
\hline $3+y e a r s$ postsecondary & 0.66 (0.59 to 0.74$)$ & 0.77 (0.68 to 0.86$)$ & $0.46(0.21$ to 0.97$)$ & $0.54(0.24$ to 1.19$)$ & $0.69(0.34$ to 1.41$)$ & 0.74 (0.36 to 1.53$)$ \\
\hline Income $<€ 40250$ & Ref & Ref† & Ref & Ref† & Ref & Ref† \\
\hline Income $\geq € 40250<€ 80500$ & $0.60(0.54$ to 0.66$)$ & $0.72(0.64$ to 0.80$)$ & 0.90 (0.48 to 1.67$)$ & 1.25 (0.60 to 2.61$)$ & 0.55 (0.30 to 1.00$)$ & 0.53 (0.27 to 1.07$)$ \\
\hline Income $\geq € 80500$ & $0.45(0.41$ to 0.50$)$ & 0.60 (0.53 to 0.68$)$ & $0.63(0.34$ to 1.84$)$ & $0.79(0.34$ to 1.84$)$ & $0.94(0.44$ to 1.97$)$ & 0.81 (0.33 to 2.01$)$ \\
\hline \multicolumn{7}{|l|}{ GP mental health counselling } \\
\hline No postsecondary education & Ref & Ref & Ref & Ref & Ref & Ref \\
\hline $1-3$ years postsecondary & $1.20(0.84$ to 1.71$)$ & $1.09(0.76$ to 1.57$)$ & $0.34(0.12$ to 0.97$)$ & $0.30(0.10$ to 0.91$)$ & $1.20(0.61$ to 2.33$)$ & 1.27 (0.65 to 2.50$)$ \\
\hline $3+$ years postsecondary & 1.31 (0.90 to 1.89$)$ & $1.21(0.83$ to 1.76$)$ & $1.26(0.50$ to 3.17$)$ & $1.03(0.38$ to 2.81$)$ & $1.23(0.59$ to 2.55$)$ & $1.30(0.62$ to 2.73$)$ \\
\hline Income $<€ 40250$ & Ref & Ref† & Ref & Ref† & Ref & Ref† \\
\hline Income $\geq € 40250<80500$ & 1.07 (0.80 to 1.43$)$ & 1.09 (0.78 to 1.53$)$ & $1.14(0.43$ to 3.05$)$ & $1.40(0.44$ to 4.47$)$ & 2.06 (1.05 to 4.02$)$ & $1.79(0.81$ to 3.97$)$ \\
\hline Income $\geq € 80500$ & 0.84 (0.62 to 1.14$)$ & 0.85 (0.57 to 1.28$)$ & $1.20(0.44$ to 3.31$)$ & $1.33(0.34$ to 3.96$)$ & $1.66(0.77$ to 3.59$)$ & 1.35 (0.52 to 3.53$)$ \\
\hline \multicolumn{7}{|l|}{ Antidepressants } \\
\hline No postsecondary education & Ref & Ref & Ref & Ref & Ref & Ref \\
\hline $1-3$ years postsecondary & 0.85 (0.71 to 1.01$)$ & $0.75(0.55$ to 1.01$)$ & 0.96 (0.52 to 1.77$)$ & 1.11 (0.47 to 2.65$)$ & $0.72(0.47$ to 1.10$)$ & $0.82(0.43$ to 1.56$)$ \\
\hline $3+$ years postsecondary & $0.69(0.57$ to 0.83$)$ & 0.69 (0.50 to 0.95$)$ & 1.17 (0.60 to 2.29$)$ & 1.40 (0.54 to 3.63$)$ & 0.65 (0.40 to 1.05$)$ & $0.86(0.42$ to 1.77$)$ \\
\hline Income $<€ 40250$ & Ref & Ref† & Ref & Ref† & Ref & Ref† \\
\hline Income $\geq € 40250<€ 80500$ & 0.67 (0.57 to 0.78$)$ & 0.71 (0.52 to 0.95$)$ & 0.77 (0.43 to 1.39$)$ & $1.29(0.51$ to 3.25$)$ & $0.67(0.43$ to 1.03$)$ & $0.53(0.25$ to 1.11$)$ \\
\hline Income $\geq € 80500$ & $0.44(0.37$ to 0.52$)$ & $0.56(0.39$ to 0.80$)$ & $0.63(0.33$ to 1.20$)$ & 1.25 (0.39 to 3.96$)$ & $0.53(0.32$ to 0.89$)$ & $0.53(0.20$ to 1.36$)$ \\
\hline \multicolumn{7}{|l|}{ Specialised servicesł } \\
\hline No postsecondary education & Ref & Ref & Ref & Ref & Ref & Ref \\
\hline 1-3 years postsecondary & 1.94 (1.24 to 3.03$)$ & 1.81 (1.13 to 2.88$)$ & 1.34 (0.52 to 3.46$)$ & $0.79(0.27$ to 2.36$)$ & $1.30(0.70$ to 2.43$)$ & $1.73(0.87$ to 3.41$)$ \\
\hline $3+$ years postsecondary & 1.91 (1.20 to 3.05$)$ & 1.92 (1.18 to 3.13$)$ & 2.01 (0.75 to 5.41$)$ & 1.41 (0.45 to 4.36$)$ & 1.25 (0.63 to 2.49$)$ & 1.67 (0.78 to 3.57$)$ \\
\hline Income $<€ 40250$ & Ref & Ref† & Ref & Ref† & Ref & Ref† \\
\hline Income $\geq € 40250<€ 80500$ & $1.03(0.75$ to 1.42$)$ & $1.11(0.76$ to 1.64$)$ & 0.67 (0.30 to 1.49$)$ & $0.79(0.36$ to 1.76$)$ & 1.32 (0.73 to 2.37$)$ & 1.47 (0.69 to 3.14$)$ \\
\hline Income $\geq € 80500$ & 0.89 (0.64 to 1.23$)$ & 0.99 (0.63 to 1.55$)$ & 0.96 (0.44 to 2.09$)$ & 1.35 (0.55 to 3.33$)$ & $1.05(0.53$ to 2.11$)$ & 1.36 (0.52 to 3.56$)$ \\
\hline
\end{tabular}

Results significant within a $95 \% \mathrm{Cl}$ are marked in bold.

${ }^{*}$ Adjusted for age group $60 \pm$ years, gender, present treatment of antidepressants, psychologist or psychiatrist.

†Adjusted for age group $60 \pm$ years, gender, present treatment of antidepressants, psychologist or psychiatrist, cohabitation.

†Psychologist or psychiatrist, public or private.

GP, general practitioner, MDI, Major Depression Inventory.

Higher education (3+years) as well as high income were associated with fewer consultations with a GP and fewer prescriptions of antidepressants, compared with those without postsecondary education or with low income. However, increased educational level was associated with more contact with specialised services (aOR 1.81, CI 1.13 to 2.88; aOR 1.92, CI 1.18 to 3.13 ); a difference not seen between the income groups.

Among respondents with symptoms of mild depression, there was no statistically significant difference across educational groups or income groups in odds for contacts and prescriptions in the adjusted analyses, except that those with 1-3years of postsecondary education had a lower use of MHC by GP (aOR 0.30 , CI 0.10 to 0.91 ) compared with respondents without any postsecondary education.

In the group with symptoms of moderate/severe depression there was no difference across socioeconomic categories in any type of healthcare contact, when adjusted for age, gender and present treatment. 
Table 3 Incidence rate ratios for mental healthcare treatments by education level and income level stratified by MDI grade

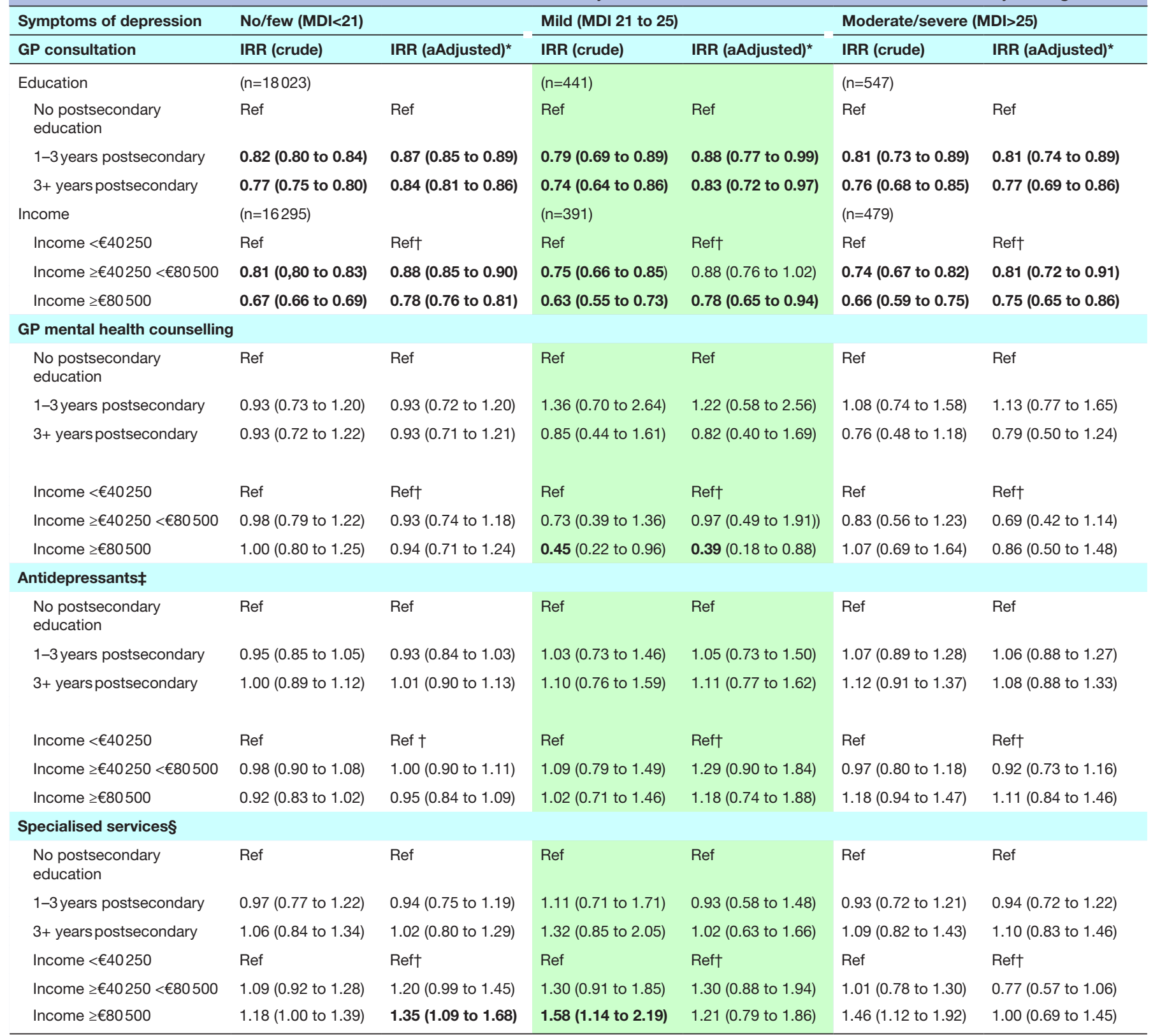

*Adjusted for age group $60 \pm$ years, gender, present treatment of antidepressants, psychologist or psychiatrist.

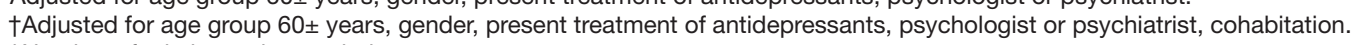

$\ddagger$ Number of reimbursed prescriptions.

§Psychologist or psychiatrist, public or private.

Results significant within a $95 \% \mathrm{Cl}$ are marked in bold.

GP, general practitioner; IRR, incidence rate ratio; MDI, Major Depression Inventory.

Table 3 shows the rate (IRR) of visits and number of prescriptions of antidepressants stratified by severity of symptoms. At all grades of symptoms of depression, short education and low income were associated with higher rates of visits to GP.

Among participants with no/few symptoms of depression, high income was associated with more frequent visits to a specialist, compared with the low income group (adjusted IRR (aIRR) 1.35, CI 1.09 to 1.68).

Among participants with mild symptoms of depression high income was associated with a lower visit rate for
GP-MHC than the low-income group (aIRR 0.39, CI 0.18 to 0.88 ).

In the group with symptoms of moderate/severe depression there were no significant differences between income groups or educational groups in visit rates to services beyond GP, when adjusted for age, gender and present treatment among those using services.

Table 4 shows the highest gained treatment level within the 180-day window in crude numbers (online supplementary table 2 shows number and mean number of MHCT by MDI grade). More severe symptoms were 


\begin{tabular}{|c|c|c|c|}
\hline $\begin{array}{l}\text { Final treatment } \\
\text { level/AMDI grade }\end{array}$ & No/few & Mild & $\begin{array}{l}\text { Moderate./ } \\
\text { severe }\end{array}$ \\
\hline No contacts & $4540(25.2)$ & $73(16.6)$ & $56(10.2)$ \\
\hline GP consultation & $12084(67)$ & $257(58.3)$ & $259(47.3)$ \\
\hline GP MHC & $160(0.9)$ & $5(1.1)$ & $20(3.7)$ \\
\hline Antidepressants ${ }^{\star}$ & $931(5.2)$ & $64(14.5)$ & $125(22.9)$ \\
\hline Psychologists & $162(0.9)$ & $17(3.9)$ & $27(4.9)$ \\
\hline Private psychiatrist & $96(0.5)$ & $18(4.1)$ & $39(7.1)$ \\
\hline $\begin{array}{l}\text { Outpatient } \\
\text { psychiatry }\end{array}$ & $17(0.1)$ & $3(0.7)$ & $7(1.3)$ \\
\hline $\begin{array}{l}\text { Admission to } \\
\text { psychiatric hospital } \\
\text { and emergency } \\
\text { access psychiatric } \\
\text { ward }\end{array}$ & $33(0.2)$ & $4(0.9)$ & $14(2.6)$ \\
\hline Sum & $18.023(100)$ & $441(100)$ & $547(100)$ \\
\hline
\end{tabular}

Per cent in brackets.

${ }^{*}$ Reimbursed prescriptions.

GP, general practitioner; MDI, Major Depression Inventory; MHC, mental health counselling. met with a higher level of treatment, though $10 \%$ of the respondents with symptoms of moderate/severe depression had no contact at all. Forty-seven per cent of the 547 with symptoms of moderate/severe depression had no treatment or contacts beyond a GP consultation.

Table 5 shows that respondents with symptoms of depression gained a significantly higher treatment level, increasing with higher symptom score, compared with those with no/few symptoms and no postsecondary education or low income (online supplementary table 3 shows highest treatment level gained within 6 months by education, income and severity of symptoms, in crude numbers and percentage.) For the group with no/few symptoms, respondents with $3+$ years of postsecondary education or higher income reached a lower level overall.

We found no statistically significant differences between educational groups stratified by grade of symptoms, but a significant increase in treatment level within each educational group when depression score increased from no/ few symptoms to symptoms of mild depression, and again when it changed to symptoms of moderate/severe depression

Table 5 Mean level of mental healthcare treatment by education level and income level and MDI grade

\begin{tabular}{|c|c|c|}
\hline No/few symptoms of depression & & $\beta$ \\
\hline Education & $0.97(n=19011)$ & \\
\hline No postsecondary education & $0.98(n=2502)$ & $(\operatorname{Ref})^{*}$ \\
\hline 1-3years postsecondary education & $0.94(n=9650)$ & $-0.06(-0.09 ;-0.03)$ \\
\hline $3+$ years postsecondary education & $0.87(n=5871)$ & $-0.05(-0.08 ;-0.02)$ \\
\hline Income & $0.96(n=17165)$ & \\
\hline Income $<€ 40250$ & $1.07(n=3850)$ & $(\operatorname{Ref}) \dagger$ \\
\hline Income $\geq € 40250<€ 80500$ & $0.93(n=6207)$ & $-0.01(-0.04 ; 0.02)$ \\
\hline Income $\geq € 80500$ & $0.81(n=6238)$ & $-0.12(-0.15 ;-0.09)$ \\
\hline \multicolumn{3}{|l|}{ Mild symptoms of depression } \\
\hline No postsecondary education & $1.49(n=93)$ & $0.15(0.01 ; 0.29)$ \\
\hline 1-3years postsecondary education & $1.47(n=225)$ & $0.14(0.05 ; 0.24)$ \\
\hline $3+$ years postsecondary education & $1.58(n=123)$ & $0.22(0.10 ; 0.35)$ \\
\hline Income $<€ 40250$ & $1.62(n=138)$ & $0.05(-0.06 ; 0.17)$ \\
\hline Income $\geq € 40250<€ 80500$ & $1.46(n=137)$ & $0.11(-0.01 ; 0.23)$ \\
\hline Income $\geq € 80500$ & $1.47(n=116)$ & $0.22(0.09 ; 0.34)$ \\
\hline \multicolumn{3}{|c|}{ Moderate/severe symptoms of depression } \\
\hline No postsecondary education & $2.18(n=136)$ & $0.37(0.26 ; 0.49)$ \\
\hline 1-3years postsecondary education & $1.99(n=257)$ & $0.35(0.26 ; 0.44)$ \\
\hline $3+$ years postsecondary education & $2.01(n=154)$ & $0.45(0.33 ; 0.56)$ \\
\hline Income $<€ 40250$ & $2.10(n=208)$ & $0.28(0.18 ; 0.37)$ \\
\hline Income $\geq € 40250<€ 80500$ & $2.06(n=164)$ & $0.40(0.29 ; 0.51)$ \\
\hline Income $\geq € 80500$ & $1.80(n=107)$ & $0.34(0.21 ; 0.47)$ \\
\hline
\end{tabular}

Results significant within a $95 \% \mathrm{Cl}$ are marked in bold.

${ }^{*}$ Adjusted for age group $60 \pm$ years, gender, present treatment of antidepressants, psychologist or psychiatrist.

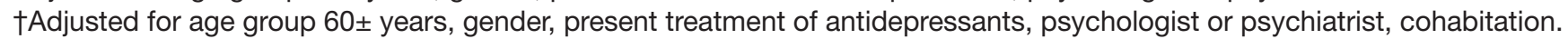

Treatment levels: 0: no contact; 1: GP consultation; 2: GP MHC; 3: Antidepressants; 4: psychologist; 5: private psychiatrist; 6: public psychiatrist; 7: psychiatric hospital and emergency visits.

GP, general practitioner; MDI, Major Depression Inventory; MHC, mental health counselling. 
(results not shown). SEP measured by income had similar outcomes, but differed in the group with mild symptoms of depression, where only respondents with high income gained a higher treatment level compared with the low income group with no/few symptoms.

\section{DISCUSSION}

Participants with symptoms of depression were treated according to the severity of the symptoms, independent of SEP; however, more than half with moderate to severe symptoms received no treatment beyond GP consultation. People in low SEP and no/few symptoms of depression were more often treated with antidepressants.

\section{Symptoms of depression and use of services}

Respondents in need and in contact with healthcare providers were treated according to their needs. This finding aligns with other studies on treatment of depres$\operatorname{sion}^{42}$ and a recent Swedish study designed as ours. ${ }^{43}$ Some studies likewise found SEP had no independent impact on the type of treatment ${ }^{1944} 45$ or intensity of treatment. ${ }^{3746}$ Yet some studies have found that higher education was associated with more use of specialised mental healthcare, even when adjusted for needs. ${ }^{47-49}$ However, beside the Swedish study all these prior studies rely on recalled service use only, however, and thus may be subject to recall bias.

\section{Symptoms of depression and no use}

A Swedish follow-up study of more than 2000 respondents with symptoms of depression (MDI $>20$ ) or anxiety likewise found that a third did not seek care at all. People with higher education were less likely to seek care at all, and if they did, they more often sought help from a psychologist. ${ }^{50}$ Other studies report that $35 \%-52 \%$ of respondents with symptoms of severe common mental disorders have no treatment contacts. ${ }^{3651}$ As in the Swedish study, we found respondents with $3+$ years of postsecondary education or high income were less likely to have contacts at all, compared with respondents without postsecondary education or low income, but these differences were not significant in the groups with symptoms of depression.

The GPs' ability to detect depression could be questioned, since only half the respondents with moderate to severe symptoms of depression are treated. When compared with ratings determined through semistructured interviews, the detection rates for depression in primary healthcare are relatively low, with a sensitivity rate of $50 \%$ and a specificity rate of $81 \%{ }^{52}$ in 2009 , and more recently in 2014, a sensitivity rate of $51 \%$ and a specificity rate of $87 \%$, when compared with a standardised instrument as the Patient Health Questionnaire-9. ${ }^{53}$ The use of depression scoring tools validated for primary care could improve detection rates; if self-administered, it would be less time-consuming for GPs and perhaps a more realistic approach. ${ }^{49}$ It is noteworthy that the proportion receiving the highest treatment level from a GP was the same across educational groups.

A German study on trends in non-help-seeking for mental disorders found a downward trend, finding that $57 \%$ of the citizens with present symptoms of a mental disorder had never sought help for a mental problem in the years $2009-2010,{ }^{54}$ this result is very similar to the findings of our study.

\section{No/few symptoms of depression and use of services}

The group that was treated, but scored with no/few symptoms of depression, may indicate emerging needs or an overuse of services. Since respondents did not each undergo additional screening by a professional, there is a lack of verification for the level of need beyond the self-reported symptoms on the inventory. However, we consider a comparison across socioeconomic groups relevant in this group, as in the other symptom groups.

First, we found no/few symptoms of depression were associated with more use of specialised mental health services for respondents with postsecondary education when compared with those with no postsecondary education, adjusting for age, gender and present treatment. Notably, when income was used as an indicator of SEP, no difference in use of specialist services was found. Other researchers have found that higher education is associated with more use of specialised services and suggest it could be due to the fact that higher-educated individuals might recognise and accept psychiatric needs more than lower-educated individuals; ${ }^{47}$ or that mental health treatment makes heavy demands on a client's cognitive capacities and this presents a greater obstacle for people with less education. ${ }^{48}$ What is seen in the group with no/ few symptoms could be the treatment of emerging mental health problems, and a result of specialised services being requested more by patients with postsecondary education, or that specialised services are a more evident first choice by the GP for some patients. We had also expected that the expenses associated with the use of psychologists in Denmark ${ }^{55}$ would have an impact, but it did not.

An Australian study found that only a small proportion $(4 \%)$ of individuals without any disorders or need indicators were among those receiving mental healthcare. Though this group comprised a fair proportion of service users, the vast majority only sought brief primary care or counselling treatment rather than consultations with psychiatrists, where they constituted only $7 \%$ of all psychiatric patients. ${ }^{56}$ That study did not relate the use of services to SEP. However, a Canadian study did find that individuals using mental healthcare and having no symptoms of mental disorders were better educated compared with those with mental disorders using the services. ${ }^{16}$

Second, we found that prescription of antidepressants was more common in the group with no/few symptoms and in low SEP. Similar findings were shown in another Australian study, where low SEP was associated with higher prescription rates not attributable to 
higher rates of depression. ${ }^{57}$ The most plausible reason for this association is that depressive disorders are more prevalent in this group and antidepressants are the first choice of treatment, or that antidepressants are more commonly used as analgesic medications in this group, as chronic pain is more common for persons with low SEP. $^{58}$

\section{Strengths and limitations}

A major strength of this study was that we were able to obtain reliable data on need from a large sample of people in GESUS as well as high-quality data on healthcare contacts and prescriptions of antidepressants from national registers, addressing challenges common in studies of equality in healthcare. ${ }^{9}$ To our knowledge, this is the first study combining survey data of depression scores and SEP with register data on MHCT. Thus we managed to avoid the inherent problem of recall bias, which is a common problem in these types of studies. ${ }^{59}$

SEP may be defined in several ways,${ }^{35}$ but in the present study we used education and income as indicators of SEP. The span of respondents seen in the sample, from a few students to a high proportion of older and retired persons, indicated that income and employment status would be less potent to differentiate the resources that respondents could be expected to have. For that reason, education was the first choice, paired with income, even though older age is associated with lower educational attainment. ${ }^{27}$ Additionally, education seems a particularly important factor when evaluating the use of healthcare specialists. $^{10}$

The study related respondents' use of services based on an indication of need (MDI score) that might not capture the fluctuations in all 6 months afterwards, which is a potential limitation. Even though need will change over time, such change would not be expected to differ among the socioeconomic groups; however, if it did, it would be expected to trend towards higher need for those in low SEP.

The actual reasons for treatment contacts were not known, nor were the reasons for prescriptions of antidepressants known; both could have been for disorders other than depression, indicating a potential limitation of the study design. The variety of other possible disorders would tend to be more common for people in low SEP, and may explain the generally higher use of GP by respondents in low SEP.

Another potential limitation is that not all services used are included in the registers. If a patient is not referred by a GP and pays the full expense for a treatment out of pocket, there is no state reimbursement and subsequently no registration of the treatment in the registers. This would usually indicate high-income individuals, which is often associated with more years of postsecondary education. We do not expect this to be a common scenario, though we have no data to support this.

\section{IMPLICATIONS}

For clinicians and policy makers it is of particular interest to know that the treatment of patients with symptoms of depression matched the severity of symptoms and was independent of the SEP of the patient.

A high proportion with symptoms of depression was not treated. Initiatives to improve mental health literacy might help people with symptoms of depression to address mental health problems when consulting their GP and thereby increase treatment rates. Better attention to mental health by the GP is also necessary, and probably a more systematic approach in evaluating patients' mental health should be implemented.

An interesting disparity between education and income on use of specialised services was found in the group with no/few symptoms. Are specialised services-most likely psychologists-the first choice for the GP when the patient has more years of postsecondary education? Is the initial treatment of patients with depressive symptoms different depending on their education, and why are the prescription rates of antidepressants much higher for persons in low SEP compared with those in high SEP? These issues deserve in-depth exploration in order to more fully address issues of health inequity.

\section{CONCLUSION}

We found no differentiation between socioeconomic groups in the treatment of respondents with symptoms of moderate to severe depression when looking at treatment contact, frequency of contacts or level of treatment. However, more than half the respondents with moderate to severe symptoms had no treatment beyond GP consultation. Respondents with no/few symptoms of depression used services differently; people in low SEP were more often treated with antidepressants than people in high SEP, whereas people with postsecondary education were more likely to receive specialist services compared with those without postsecondary education, though this association was not found for income.

\section{Author affiliations}

${ }^{1}$ Department of Public Health, Research Unit for General Practice, University of Southern Denmark, Odense, Denmark

${ }^{2}$ Region Zealand, Psychiatry, Psychiatric Research Unit, Slagelse, Denmark

${ }^{3}$ Center for Primary Health Care Research, Faculty of Medicine, Lund University, Lund, Sweden

${ }^{4}$ Department of Clinical Medicine, Psychiatric Research Unit, University of Copenhagen, Copenhagen, Denmark

${ }^{5}$ Department of Public Health and Research Unit of Clinical Epidemiology, Institute of Clinical Research, University of Southern Denmark, Odense, Denmark

Acknowledgements The authors thank Professor Mogens Vestergaard, Department of Public Health, Aarhus University, Denmark, for comments and contributions in the initial stage of the study. The authors also thank GESUS for sharing data, the Health Research Foundation of Region Zealand for financial support and former head nurse Tove Kjærbo for initiating the study.

Contributors The statistical analyses were performed by statistician SW. AP conceived the research and wrote the first draft of the manuscript assisted by FBW. FBW contributed substantially to the study design and choice of analysis. AH, 
ES and LHH contributed to data analysis, interpretation of the results and critical revision of the manuscript.

Funding The study has been supported by an unrestricted grant (No 15-000342) from the Health Research Foundation of Region Zealand.

Competing interests None declared.

Patient consent Obtained.

Provenance and peer review Not commissioned; externally peer reviewed.

Data sharing statement No additional data are available.

Open access This is an open access article distributed in accordance with the Creative Commons Attribution Non Commercial (CC BY-NC 4.0) license, which permits others to distribute, remix, adapt, build upon this work non-commercially, and license their derivative works on different terms, provided the original work is properly cited, appropriate credit is given, any changes made indicated, and the use is non-commercial. See: http://creativecommons.org/licenses/by-nc/4.0/.

\section{REFERENCES}

1. OECD. Health policies and data: Health Inequalities. 2017 http:// www.oecd.org/els/health-systems/inequalities-in-health.htm (updated 11 Jun 2017).

2. World Health Organization. Health 2020. A European policity framework and strategy for the 21st century. Copenhagen, 2013:1-184.

3. Lynch JW, Kaplan GA, Shema SJ. Cumulative impact of sustained economic hardship on physical, cognitive, psychological, and social functioning. N Engl J Med 1997;337:1889-95.

4. Ahnquist J, Wamala SP. Economic hardships in adulthood and mental health in Sweden. The Swedish National Public Health Survey 2009. BMC Public Health 2011;11:788.

5. Lorant $\mathrm{V}$, Deliège $\mathrm{D}$, Eaton $\mathrm{W}$, et al. Socioeconomic inequalities in depression: a meta-analysis. Am J Epidemiol 2003;157:98-112.

6. Lorant V, Croux C, Weich S, et al. Depression and socio-economic risk factors: 7-year longitudinal population study. Br J Psychiatry 2007;190:293-8.

7. Muntaner C, Eaton WW, Miech R, et al. Socioeconomic position and major mental disorders. Epidemiol Rev 2004;26:53-62.

8. Dohrenwend BP, Levav I, Shrout PE, et al. Socioeconomic status and psychiatric disorders: the causation-selection issue. Science 1992;255:946-52.

9. World Health Organization. Depression and Other Common Mental Disorders: Global Health Estimates. Geneva 2017:1-24.

10. Laursen TM, Musliner KL, Benros ME, et al. Mortality and life expectancy in persons with severe unipolar depression. J Affect Disord 2016;193:203-7.

11. Goddard M, Smith P. Equity of access to health care services: theory and evidence from the UK. Soc Sci Med 2001;53:1149-62.

12. Fjær EL, Balaj M, Stornes $P$, et al. Exploring the differences in general practitioner and health care specialist utilization according to education, occupation, income and social networks across Europe: findings from the European social survey (2014) special module on the social determinants of health. Eur $\mathrm{J}$ Public Health 2017;27-73-81.

13. Hanratty B, Zhang T, Whitehead M. How close have universal health systems come to achieving equity in use of curative services? A systematic review. Int J Health Serv 2007;37:89-109.

14. ten Have M, ledema J, Ormel J, et al. Explaining service use for mental health problems in the Dutch general population: the role of resources, emotional disorder and functional impairment. Soc Psychiatry Psychiatr Epidemiol 2006;41:285-93.

15. Andrews $\mathrm{G}$, Issakidis $\mathrm{C}$, Carter $\mathrm{G}$. Shortfall in mental health service utilisation. Br J Psychiatry 2001;179:417-25.

16. Kohn R, Saxena S, Levav I, et al. The treatment gap in mental health care. Bull World Health Organ 2004;82:858-66.

17. Lin E, Goering P, Offord DR, et al. The use of mental health services in Ontario: epidemiologic findings. Can J Psychiatry 1996;41:572-7.

18. Fleury MJ, Ngui AN, Bamvita JM, et al. Predictors of healthcare service utilization for mental health reasons. Int J Environ Res Public Health 2014;11:10559-86.

19. Glozier N, Davenport T, Hickie IB. Identification and management of depression in Australian primary care and access to specialist mental health care. Psychiatr Serv 2012;63:1247-51.

20. Boerema AM, Ten Have M, Kleiboer A, et al. Demographic and need factors of early, delayed and no mental health care use in major depression: a prospective study. BMC Psychiatry 2017;17:367.
21. Hansen $\mathrm{AH}$, Høye A. Gender differences in the use of psychiatric outpatient specialist services in Troms $\varnothing$, Norway are dependent on age: a population-based cross-sectional survey. BMC Health Serv Res 2015;15.

22. Dezetter A, Duhoux A, Menear M, et al. Reasons and Determinants for Perceiving Unmet Needs for Mental Health in Primary Care in Quebec. Can J Psychiatry 2015;60:284-93.

23. Evans-Lacko S, Aguilar-Gaxiola S, Al-Hamzawi A, et al. Socioeconomic variations in the mental health treatment gap for people with anxiety, mood, and substance use disorders: results from the WHO World Mental Health (WMH) surveys. Psychol Med 2018;48:1-12.

24. Packness A, Waldorff FB, Christensen RD, et al. Impact of socioeconomic position and distance on mental health care utilization: a nationwide Danish follow-up study. Soc Psychiatry Psychiatr Epidemiol 2017;52:1405-13.

25. Pedersen KM, Andersen JS, Søndergaard J. General practice and primary health care in Denmark. J Am Board Fam Med 2012;25 Suppl 1(Suppl 1):S34-S38.

26. Larsen A. Psykologbehandling. 2014. www.sundhed.dk. www. sundhed.dk/borger/sygdomme-a-aa/sociale-ydelser/sociale-ydelser/ behandling/psykologbehandling/ (updated 29 sep 2014).

27. Bergholdt HK, Bathum L, Kvetny J, et al. Study design, participation and characteristics of the Danish General Suburban Population Study. Dan Med J 2013;60:A4693. A4693.

28. Økonomi- og Indenrigsministeriet. Indenrigsministeriet $\varnothing$-o, ed. [Alligenment between municipalities and general subsidizes 2014] Kommunal udligning og generelle tilskud 2014. København, 2013.

29. Pedersen CB. The Danish Civil Registration System. Scand J Public Health 2011;39(7 Suppl):22-5.

30. Olsen LR, Jensen DV, Noerholm V, et al. The internal and external validity of the Major Depression Inventory in measuring severity of depressive states. Psychol Med 2003;33:351-6.

31. World Health Organization. The $I C D-10$ Classification of Mental and Behavioural Disorders, 1995.

32. Bech P, Timmerby N, Martiny K, et al. Psychometric evaluation of the Major Depression Inventory (MDI) as depression severity scale using the LEAD (Longitudinal Expert Assessment of All Data) as index of validity. BMC Psychiatry 2015;15:190.

33. Sundhedsstyrelsen. Referenceprogram for treatment of unipolar depression in adults. (SfR) SfR. ed. Copenhagen, 2007:1-138.

34. Bech P. Clinical Psychometrics. First ed. Oxford: John Wiley \& Sons, Ltd, 2012:153-53.

35. Galobardes B, Shaw M, Lawlor DA, et al. Indicators of socioeconomic position (part 1). J Epidemiol Community Health 2006;60:7-12

36. Andersen JS, Olivarius NF, Krasnik A. The Danish National Health Service Register. Scand J Public Health 2011;39(7 Suppl):34-7.

37. Kildemoes HW, Sørensen HT, Hallas J. The Danish National Prescription Registry. Scand J Public Health 2011;39(7 Suppl):38-41.

38. World Health Organization CCfDSM. Guidelines for ATC classification and DDD assignment 2014. 17 ed. Oslo: Norwegian Institute of Public Health, 2013:1-273.

39. Lynge E, Sandegaard JL, Rebolj M. The Danish National Patient Register. Scand J Public Health 2011;39(7 Suppl):30-3.

40. Stata Statistical Software: Release 14. [program]. 1 version: College Station,TX:StataCorp LP.]. 2015.

41. Denmark S. StatBank Denmark [Public Database]. Statistics Denmark. www.statistikbanken.dk (accessed 11 Nov 2015).

42. McCracken C, Dalgard OS, Ayuso-Mateos JL, et al. Health service use by adults with depression: community survey in five European countries. Evidence from the ODIN study. Br J Psychiatry 2006;189:161-7

43. Sun Y, Möller J, Lundin A, et al. Utilization of psychiatric care and antidepressants among people with different severity of depression: a population-based cohort study in Stockholm, Sweden. Soc Psychiatry Psychiatr Epidemiol 2018;53:607-15.

44. Gabilondo A, Rojas-Farreras S, Rodríguez A, et al. Use of primary and specialized mental health care for a major depressive episode in Spain by ESEMeD respondents. Psychiatr Serv 2011;62:152-61.

45. Dey M, Jorm AF. Social determinants of mental health service utilization in Switzerland. Int J Public Health 2017;62:85-93.

46. Ten Have M, Nuyen J, Beekman A, et al. Common mental disorder severity and its association with treatment contact and treatment intensity for mental health problems. Psychol Med 2013;43:2203-13.

47. Hansen $\mathrm{AH}$, Halvorsen PA, Ringberg U, et al. Socio-economic inequalities in health care utilisation in Norway: a population based cross-sectional survey. BMC Health Serv Res 2012;12:336.

48. Have M, Oldehinkel A, Vollebergh W, et al. Does educational background explain inequalities in care service use for mental health 
problems in the Dutch general population? Acta Psychiatr Scand 2003;107:178-87.

49. Vasiliadis HM, Tempier R, Lesage A, et al. General practice and mental health care: determinants of outpatient service use. Can $J$ Psychiatry 2009;54:468-76.

50. Wallerblad A, Möller J, Forsell Y. Care-Seeking Pattern among Persons with Depression and Anxiety: A Population-Based Study in Sweden. Int J Family Med 2012;2012:1-9.

51. Perkins D, Fuller J, Kelly BJ, et al. Factors associated with reported service use for mental health problems by residents of rural and remote communities: cross-sectional findings from a baseline survey. BMC Health Serv Res 2013;13:157.

52. Mitchell AJ, Vaze A, Rao S. Clinical diagnosis of depression in primary care: a meta-analysis. The Lancet 2009;374:609-19.

53. Carey M, Jones K, Meadows G, et al. Accuracy of general practitioner unassisted detection of depression. Australian \& New Zealand Journal of Psychiatry 2014;48:571-8.

54. Brandstetter S, Dodoo-Schittko F, Speerforck S, et al. Trends in nonhelp-seeking for mental disorders in Germany between 1997-1999 and 2009-2012: a repeated cross-sectional study. Soc Psychiatry Psychiatr Epidemiol 2017;52:1005-13.

55. Kiil A, Houlberg K. How does copayment for health care services affect demand, health and redistribution? A systematic review of the empirical evidence from 1990 to 2011. The European Journal of Health Economics 2014;15:813-28.

56. Bobevski I, Rosen A, Meadows G. Mental health service use and need for care of Australians without diagnoses of mental disorders: findings from a large epidemiological survey. Epidemiol Psychiatr Sci 2017:19:1-11.

57. Butterworth P, Olesen SC, Leach LS. Socioeconomic differences in antidepressant use in the PATH through life study: Evidence of health inequalities, prescribing bias, or an effective social safety net? $J$ Affect Disord 2013;149(1-3):75-83.

58. Riskowski JL. Associations of Socioeconomic Position and Pain Prevalence in the United States: Findings from the National Health and Nutrition Examination Survey. Pain Medicine 2014;15:1508-21.

59. Brusco NK, Watts JJ. Empirical evidence of recall bias for primary health care visits. BMC Health Serv Res 2015;15:381. 